\title{
Mechanical Properties of Woven Mat Jute/Epoxy Composites
}

\author{
José Martins Ferreira ${ }^{a}$, Carlos Capela ${ }^{a, b *}$, João Manaia ${ }^{b}$, José Domingos Costa ${ }^{a}$ \\ ${ }^{a}$ Centre for Mechanical Engineering of the University of Coimbra-CEMUC, Mechanical Engineering \\ Department, University of Coimbra, Coimbra, Portugal \\ ${ }^{b}$ School of Technology and Management - ESTG, Mechanical Engineering Department, Polytechnic \\ Institute of Leiria, Leiria, Portugal
}

Received: July 22, 2015; Revised: January 27, 2016; Accepted: April 4, 2016

\begin{abstract}
Natural fibers combine technological, economic and ecological aspects. However, a major restriction on their successful use in long term composite applications is their high moisture absorption and poor dimensional stability. This paper is aimed at establishing a link between the mats grammage and the mechanical properties of the epoxy/jute fibers laminates. Composites reinforced by coarse, medium and fine $(\mathrm{C}, \mathrm{M}$ and $\mathrm{F})$ mats were processed by vacuum bagging. Some batches were immersed in water up to 60 days in order to study the hydro-degradation. Mechanical tests were performed to obtain the bending strength and impact response. The mechanical response to bending and impact loadings was conditioned not only by the percentage of fiber, but also by the thickness of the specimens, which leads to composites $\mathrm{F}$ having lower strength than composites $\mathrm{C}$ despite having a higher percentage of fiber. Immersion in water causes a marked loss of mechanical properties in the first days of immersion, especially for thinner fiber grammage composites. A strong influence of the mats grammage on the impact response was observed. Increasing mats grammage promotes a strong increase in peak load, restored energy and impact energy for perforation and also a marked reduction of the deformation.
\end{abstract}

Key-words: Composites, jute, natural fibers, mechanical properties, impact response

\section{Introduction}

Nowadays, consumers are increasingly concerned with sustainability issues brought about by the resource and environmental protection. Therefore, environmentally friendly, natural, recycled, or biodegradable materials have become quite attractive ${ }^{1,2}$. Natural fibers, a new group of environmentally friendly materials, have been in considerable demand in recent years. These fibers combine technological, economic and ecological aspects ${ }^{3}$, play a key role in the emerging "green" economy, and are being widely used in automotive applications ${ }^{4}$. Vegetable fibers are low cost, abundant and have low environmental impact, since they are biodegradable and easily recyclable ${ }^{5,6}$. Lingo-cellulosic fibers possess low density, are sometimes equivalent to glass fibers in terms of stiffness. Therefore, there has been a growing interest in the use as reinforcing fibers in polymeric composites $^{7-12}$.

The mechanical properties of composite materials depend on many factors, which include fiber length, shape, size, composition, orientation and distribution, as well as volume fraction, mechanical properties of the polymer matrix, manufacturing techniques and adhesion or connection between the fibers and the matrix ${ }^{13}$. Fiberglass has been used since the 1930s and it is most commonly used in reinforcing polymer matrix composites. One of the main causes of mechanical properties loss in composites reinforced with fiberglass is their susceptibility to moisture absorption ${ }^{14}$. The epoxy resins belong to the group of thermosetting resins and have a wide

* e-mail: ccapela@ipleiria.pt range of applications in the aerospace, automotive and marine industries, among others. In the production of composite materials reinforced with vegetable fibers, the hydrophilic nature of the epoxy resins becomes attractive due to its high affinity with this type of fibers (hydrophilic nature).

Kenaf, sisal, banana, jute flax, pulp, wood flour, oil palm, pineapple leaf and coir are the main natural fibers used as composite reinforcement $t^{4}$. The fact that jute fibers are $100 \%$ biodegradable, associated with their good mechanical strength, allows the replacement of synthetic fibers in applications where resistance is not a determining factor. The disadvantages include a decrease in strength when wet and that it also becomes subject to microbial attack in humid climates, yellowing in sunlight. According to Alves C. et al $^{15}$ the typical properties of jute fibers are: density: $1.5 \mathrm{~g} / \mathrm{cm} 3$; tensile strength: 393-773 MPa; elastic modulus: 10-30 GPa.

The anatomical origin of the fiber is a determining factor in the final properties of the processed composite material, because fibers of different origins generally have different properties. Besides that, species, age, growing conditions, weather conditions and the extraction techniques are also factors to take into account in the properties of fibers ${ }^{16}$. Along their length, vegetable fibers have defects which constitute weakness points, affecting not only the respective mechanical properties, but also the physical properties ${ }^{17}$.

From a structural point of view, vegetable fibers are multicellular in nature, consisting of a number of continuous cells with different sizes, shapes and arrangements for different types of fibers. The central region of some vegetable 
fibers can have a cavity termed "lacuna", surrounded by many lumens within its cellular structure. The lacuna and the lumens are responsible for these fibers' high capacity of water absorption. A major limitation of vegetable fibers in durable composite applications is their high moisture absorption and poor dimensional stability (swelling), as well as their susceptibility to rotting. Fiber swelling can lead to micro-cracking of the composite and, consequently, to the degradation of mechanical properties ${ }^{18,19}$.

The hygroscopic nature of natural fibers has a primary role in the study of long-term properties, including the water aging of natural fiber reinforced composites. Bledzki et $a l^{20}$ have studied the wood filled thermoplastic composites and found that after immersing the samples for 28 days in water, the mechanical properties decreased by 8 to $35 \%$. Thwe and $\mathrm{Liao}^{21}$ investigated the environmental effect on bamboo-glass/polypropylene hybrid composites, concluding that the tensile and flexural strengths of the bamboo fiber reinforced composites reduce $7.5-32 \%$ with absorption time and temperature from 25,50 and $75^{\circ} \mathrm{C}$. Other researchers studied the water aging of natural fiber composites, reporting that water uptake and water diffusion coefficient also increased with fiber content ${ }^{22-24}$.

A recent study by Y. Yang et $a l^{25}$ investigated the effect of hot water immersion on the tensile properties of injection molded jute/polypropylene composites (Jute/PP) with different fiber contents. They found that the tensile modulus increased linearly with the increasing content of jute fibers, while the tensile strength increased initially and decreased at jute fiber content above $30 \mathrm{wt} \%$. Both properties decreased significantly by aging in jute/PP with higher fiber content, as a result of the degradation of the interfacial adhesion between jute fiber and PP.

This paper is focused on the characterization of the epoxy composite materials produced with different woven mesh size jute fibers and processed by vacuum bagging, in terms of flexure mechanical properties and impact response. Taking into account the hygroscopic nature of natural fibers, the aging degradation promoted by immersion in water at room temperature was also investigated in terms of the flexural properties.

\section{Experimental and material fabrication}

The composite laminates were manufactured using epoxy resin matrix reinforced by four layers of jute fiber mats by a vacuum bagging technique. Three types of bidirectional woven jute fiber mats were used, each with different grammage and mesh size, acquired from Arraiolar Company, Portugal. The epoxy resin used was SR 1500, formulated by bisphenol $\mathrm{A}$ and $\mathrm{F}$ and it was combined with the hardener SD 2503, both supplied by Sicomin, Marseille, France. This epoxy system has good waterproof and adhesion properties and is commonly used in the ship building and aerospace industries. The resin and hardener were taken in the mixing ratio of $100(\mathrm{~g}) / 30$ (g) parts by weight, respectively.

The average fiber diameter was obtained by microscopic analysis. For this purpose, the morphologies of the cross sections of the specimens in regions rich in longitudinal fibers were analyzed using a scanning electron microscope (SEM), Siemens XL 30. The samples were cleaned by ultrasound and coated with a thin layer of gold. The accelerating voltage used was $5 \mathrm{kV}$. Fig. 1 shows an example of a SEM image. Fiber diameter was obtained from these pictures by direct measurements in a statistical analysis. Average values are much closer to the three grammage mats in order of $85 \pm 24 \mu \mathrm{m}$.

Due to the strong hydrophilic character of jute fibers, they were subjected to a drying process for 12 hours in an air circulating oven at $140^{\circ} \mathrm{C}$, in order to remove any moisture present in the fibers and hence promote better adhesion between the fiber and resin. The mould was coated with polyvinyl alcohol (releasing agent) so that the materials could be easily removed. The hand lay-up technique was used to impregnate the composite structures. Laminated composite plates were manufactured by alternating layers of woven jute fiber mat with epoxy resin. The fiber layers were oriented in the same direction. Fig. 2a) shows a schematic representation of the lay-up technique, while Fig. 2b) is a photo of the vacuum bagging manufacturing process.

After the 24-hour cure cycle at the temperature of $20^{\circ} \mathrm{C}$, all laminated plates were post-cured in an air circulating oven at a temperature of $60{ }^{\circ} \mathrm{C}$ for 16 hours, as recommended by the manufacturer. The relative vacuum pressure was always the same ( -0.9 bar), causing the laminate thickness to become dependent on the grammage of the fiber mats. The average thickness of the plates was 4.2,3.1 and $2.7 \mathrm{~mm}$, for composites with thick, medium and thin woven jute, respectively.

In order to obtain the volume fraction and porosity the weight of fiber, and resin and also the volume of the composite sample were measured. Weight of fiber, and resin were converted in theoretical volumes using the correspondent values of densities. Difference between experimental and theoretical volumes of the sample was assumed as the porosity. Table 1 summarizes the manufacturing parameters of the three composite laminates, indicating: the type and grammage of the fibers, fiber percentage in volume, porosity and the average thickness.

Experimental mechanical tests were performed under three points bending in order to obtain both flexural strength and flexural stiffness of the three composite laminates. The impact response of the laminates, Dynamic Mechanical

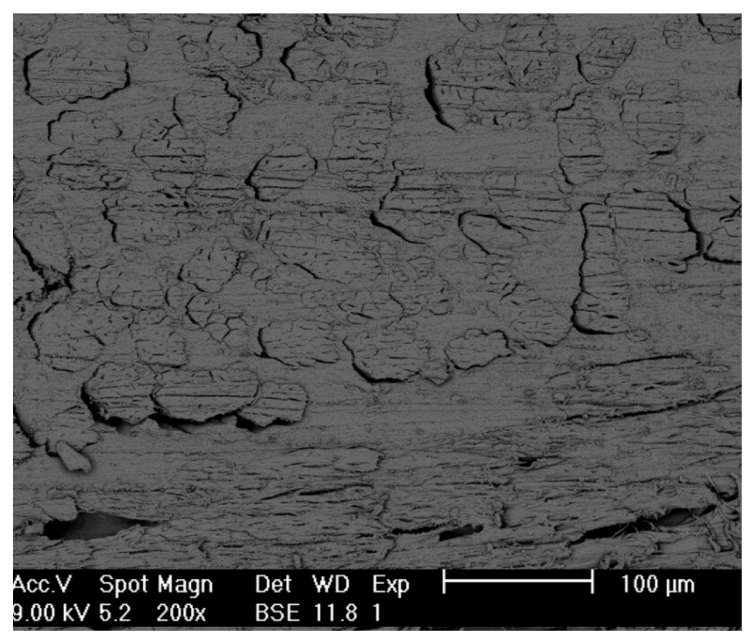

Figure 1. SEM cross view of the fiber distribution. 

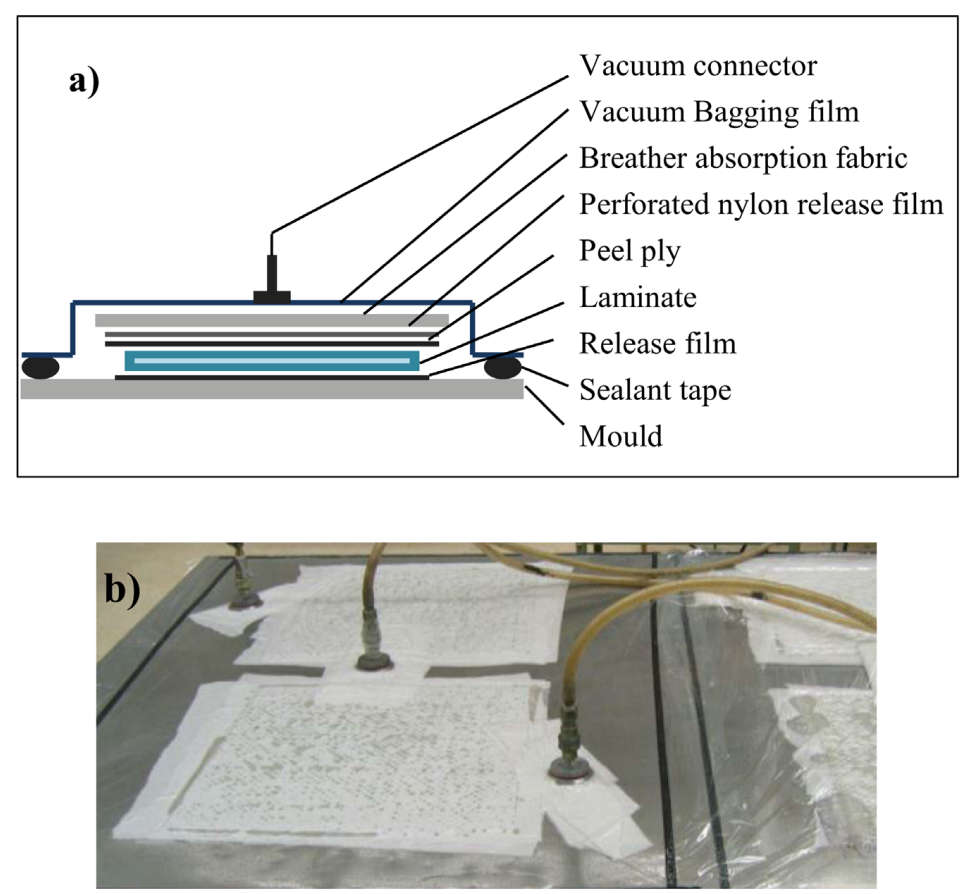

Figure 2. a) Schematic representation of the lay-up technique; b) laminated composite plates.

Table 1. Manufacturing parameters.

\begin{tabular}{cccccc}
\hline $\begin{array}{c}\text { Composite } \\
\text { reference }\end{array}$ & $\begin{array}{c}\text { Fiber } \\
\text { type }\end{array}$ & $\begin{array}{c}\text { Fiber mat } \\
\text { grammage }\left(\mathbf{g} / \mathbf{m}^{\mathbf{2}}\right)\end{array}$ & $\begin{array}{c}\text { Fiber volume } \\
\text { fraction } \mathbf{( \% )}\end{array}$ & $\begin{array}{c}\text { Porosity } \\
\mathbf{( \% )}\end{array}$ & $\begin{array}{c}\text { Laminate thickness } \\
(\mathbf{m m})\end{array}$ \\
\hline $\mathrm{C}$ & Thick woven mat & 459 & 29.2 & 16 & 4.2 \\
$\mathrm{M}$ & Medium woven mat & 367 & 31.5 & 19 & 3.1 \\
$\mathrm{~F}$ & Thin woven mat & 311 & 30.7 & 35 & 2.7 \\
\hline
\end{tabular}

Analysis (DMA) and water absorption tests were also carried out. Specimens with the required size were individually cut from the manufactured laminates using a band saw table. The cut edges were then smoothed using 240 Grade SiC paper. The dimensions of the specimens for the flexural tests and water absorption were $75 \mathrm{~mm}$ length by $12 \mathrm{~mm}$ width. The specimen's dimensions for the dynamic mechanical analysis (DMA) were $46 \mathrm{~mm}$ length by $3 \mathrm{~mm}$ width, while the samples for impact tests were $100 \times 100 \mathrm{~mm}^{2}$ square plates.

Moisture diffusion in a composite depends on factors such as fiber volume fraction, voids, matrix and temperature ${ }^{26}$. Water uptake tests were performed according to the ASTM D570-98 experimental procedure: the specimens were placed in an oven at $100{ }^{\circ} \mathrm{C}$ for 2 hours in order to remove moisture and weighed after cooling; then, they were immersed in distilled water at room temperature $\left(20^{\circ} \mathrm{C}\right)$; afterwards, the water absorption was periodically measured (weight gain). For this, the specimens were withdrawn from the water at intervals of predetermined time, wiped and dried with a tissue paper to remove the surface moisture, and then weighed. After the weighing, the specimens were immediately immersed again in distilled water. This procedure was repeated for 21 days until they reached the limit of saturation (constant weight). The weight was measured using a Mettler Toledo AG 204 analytical balance.
The water gain percentage ( $W \%$ ) was determined by equation (1),

$W(\%)=\frac{W_{t}-W_{O}}{W_{O}} \times 100$

where: $W_{t}$ is the wet weight of the specimen at time $t$ of immersion in water and $W_{0}$ is the initial weight of the dry specimen.

One of the main concerns about the usage of vegetable fibers as reinforcement in composite materials is their susceptibility to moisture absorption and its effect on the mechanical properties of said fibers. To evaluate this effect, dry specimens and wet specimens after 2, 15, 30 and 60 days immersed in distilled water at room temperature, were tested in bending. The tests were performed in three-point bending loading with a span of $40 \mathrm{~mm}$, with nominal span/thickness about 10, using a Shimadzu AG-10 universal testing machine equipped with a $5 \mathrm{kN}$ load cell and TRAPEZIUM software at a displacement rate of $1 \mathrm{~mm} / \mathrm{min}$ at room temperature $\left( \pm 20^{\circ} \mathrm{C}\right.$ ) and according to the ASTM D638 standard.

Bending strength was calculated as the maximum bending stress at middle span section using the load peak of the load versus displacement curves. The stiffness modulus 
was calculated by equation (2) according to the linear elastic beam theory,

$$
E=\frac{\Delta P L^{3}}{48 \Delta u I}
$$

where: I is the inertia moment of the transverse section and $\Delta \mathrm{P}$ and $\Delta \mathrm{u}$ are, respectively, the load range and flexural displacement range at middle span for an interval in the linear region of load versus displacement plot. The stiffness modulus was obtained by linear regression of the load-displacement curves. Taking in to account some non-linearity of the load-displacement curves, the correlation coefficient of linear regression decreases when the segment size increases. The value of the stiffness considered in this work was that corresponding to a correlation coefficient of $0.998 \%$.

Dynamic mechanical analysis (DMA) is widely used to determine relative stiffness and damping characteristics of polymeric and composite materials ${ }^{27}$. The dynamic mechanical analysis was conducted by a Perkin DMA 8000 , using the corresponding software to collect and analyze the experimental data. The DMA tests were performed according to the DIN 53457 standard in three-point bending with a span of $20 \mathrm{~mm}$, at the temperature range from $18^{\circ} \mathrm{C}$ to $90^{\circ} \mathrm{C}$ at a heating rate of $2^{\circ} \mathrm{C} /$ minute.

Low-velocity impact tests were performed using a drop weight-testing machine, CEAST 9350. A semi-spherical tip impactor with $3.4 \mathrm{~kg}$ of mass was used. The tests were performed according to ASTM D3763 standard on square section samples of 100x100 mm and the impactor stroke, at the centre of the samples, using a circular $75 \mathrm{~mm}$ diameter support. The impact energies were previously selected in order to enable the measuring of the damage area, but without promoting perforation for the majority of the specimens. For each condition, 3-4 specimens were tested at room temperature.

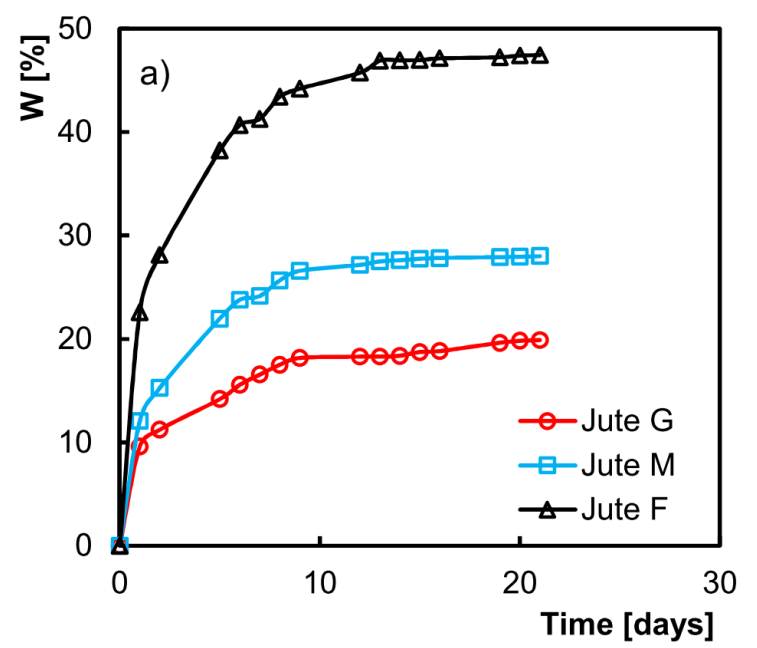

\section{Results and discussion}

The water absorption curves were obtained by immersing the specimens in distilled water up to 21 days. Three specimens were used for each laminated composite. Fig. 3a) shows the average values of the percentage of weight gain as a function of water immersion time. For the three composites, the water absorption kinetics decreased until equilibrium (constant weight) depending on the fiber grammage. Water absorption rate is fast in the early stages, corresponding to the first two-day of water immersion time. The saturation state was attained with a maximum moisture content of about $47 \%, 28 \%$ and $20 \%$ for laminates F, M and $\mathrm{C}$, respectively. Therefore, the composite material reinforced with thinner mesh size (F) absorbs much more water than the other two materials caused by its higher level of porosity. The composite material reinforced with coarse mesh size (C) presents the lower maximum moisture content in agreement with its lower level of porosity. The diffusion behaviors can be modeled by equation (3),

$\frac{M_{t}}{M_{\dot{a}}}=k_{n} t^{n}$

where $M_{t}$ is the water absorption at time t, $M \alpha$ is the water absorption at saturation point or infinite time, kn and $n$ are the constants. Depending of exponent $n$ the diffusion process can be classified as: supercase II $(n>1)$, case II $(n=1)$, anomalous $(1 / 2<n<1)$, classical/Fickian $(n=1 / 2)$, or pseuso-Fickian $(\mathrm{n}<1 / 2)^{28-30}$.

Figure $3 b$ ) shows the variation of $\log \mathrm{Mt} / \mathrm{M} \alpha$ versus $\log \mathrm{t}$ (days) for three types of bidirectional woven jute fiber mats. Linear regression lines were fitted by least-mean squares, with slopes ranging between $0.46-0.50$, indicates that three composites show a close Fickian diffusion.

Current results agrees with Leman et $\mathrm{al}^{28}$, which studied the moisture absorption of sugar palm fiber reinforced epoxy composite and observe that higher fiber composition present the higher moisture absorption rate.

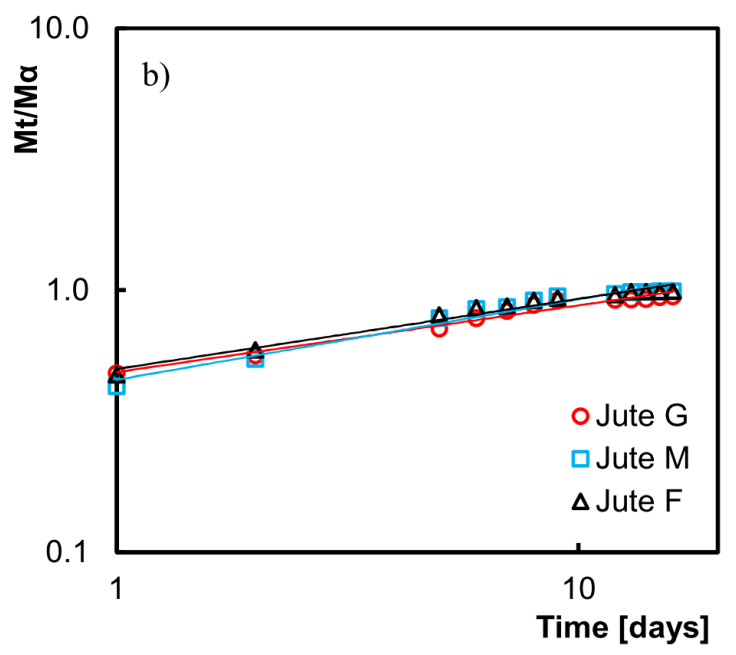

Figure 3. Water absorption results: a) water absorption versus time; b) Mt/M $\alpha$ versus time. 
Fig. 4 shows representative bending stress versus displacement curves obtained from three-point bending tests performed on dry laminated composites. Higher grammage mats laminates shows higher values of stiffness and bending stress at peak load, but lower strain at failure, which indicates that a coarser interwoven promotes the strengthening of the material.

Fig. 5 shows the average data (and the minimum-maximum interval) of bending strength $\left(\sigma_{\max }\right)$ versus the number of days of immersion in water. Each value represents an average data of five specimens. A sudden decrease in the bending strength of woven jute fiber laminates with the time of immersion in water was observed, followed by a tendency to stabilization for higher immersion times. The marked loss of mechanical properties in the first days of immersion in water may be caused by the degradation of the fibers; jute fibers have a central hollow region responsible for high water absorption capacity, which may cause swelling, resulting in the generation of micro-cracks in the fiber-matrix interface ${ }^{18}$. Composites with fine jute show a higher loss in resistance, as a result of the increase on fiber degradation promoted by a greater water absorption. For long immersion time, composites with fine jute have a bending strength about 35\% lower than composites with coarse jute. However, the thin jute composites also have lower resistance than the other even

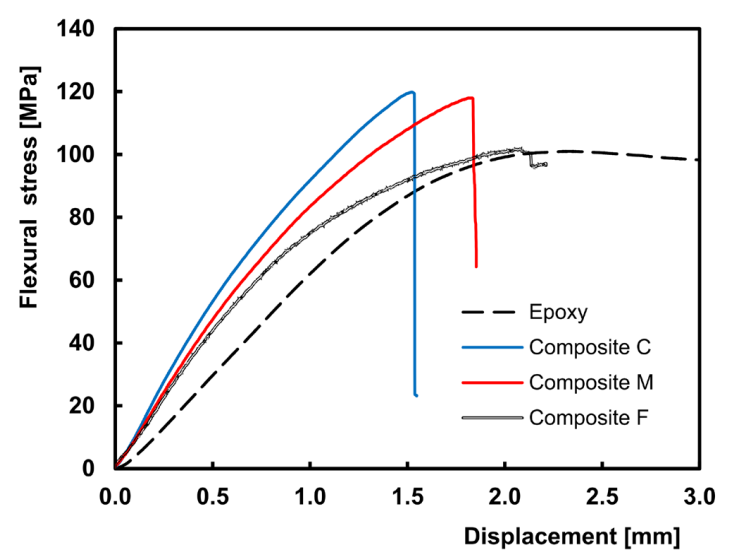

Figure 4. Curves of the flexural stress versus the displacement.

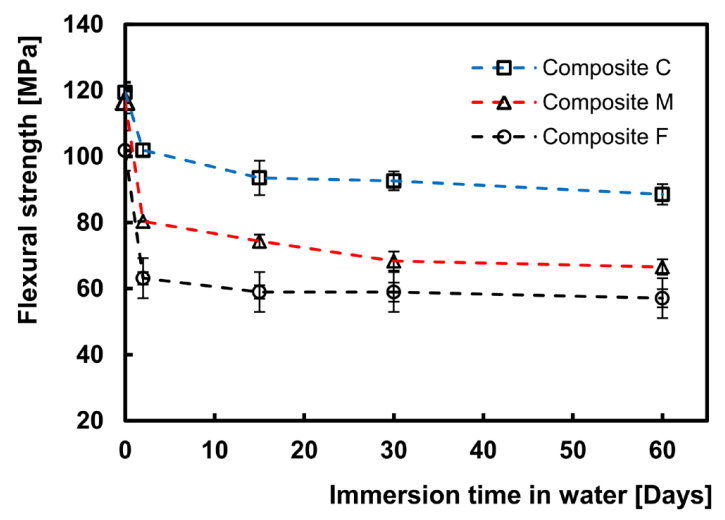

Figure 5. Bending strength versus immersion time in water. when they were not immersed in water, but, in spite of that, they have similar percentage of fiber in volume. Therefore, the higher level of porosity observed in the case of fine jute composites must be the main cause for the observed greater loss of bending strength.

Figure 6 shows the average data (and the minimummaximum interval) of flexural modulus against the time of immersion in water. The effect of the water in the flexural modulus is very similar to the one already observed for the bending strength. A great decrease in the average values was also observed after few days of immersion in water, and afterwards only a slightly decreasing occurred.

Comparing the bending stiffness of the composites immersed during 60 days with non-immersed specimens, it was observed a reduction of $42 \%, 48 \%$ and $53 \%$, for composites with coarse, medium and fine jute, respectively, indicating that degradation effect has a direct relation with the percentage of absorbed water. The stiffness of non-immersed specimens also shows a non-expected behavior. The coarse and medium jute composites have closed stiffness while thin jute composites have lower stiffness than the others, even with a similar percentage of fiber in volume. The results show a significant and not totally expected influence of grammage on the rigidity, strength and deformation at rupture. However, since all tests were performed in 3 point bending, it's possible that these results can be justified with the variation of the thickness of the specimens and the variation of porosity. Thus, the samples made with higher grammage fiber have significantly greater thickness, thus becoming more rigid in spite of its similar fiber volume fractions. The increase of thickness contributes to greater stiffness, lower strain at break and eventually higher strength. Expert et $\mathrm{al}^{29}$ studied the effect of water absorption on polypropylene matrix composite natural fibers, and obtained also a significant decrease in mechanical properties with the increase of water absorption, namely in Young's modulus and stress at maximum load.

Other parameters that may contribute to the observed behavior are the dispersion and fiber/resin adhesion. To analyze these parameters the cross section of the specimens was observed using SEM. Figures 7 a), b) and c) show pictures of the cross sections of composites manufactured by fine,

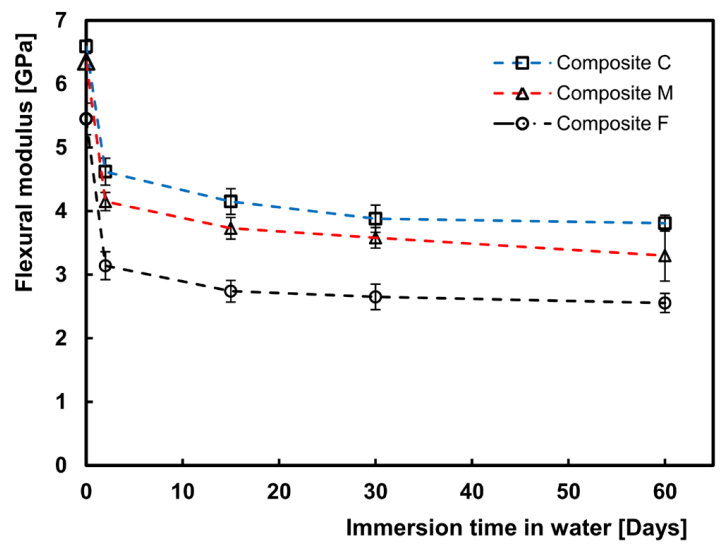

Figure 6. Flexural modulus versus immersion time in water. 

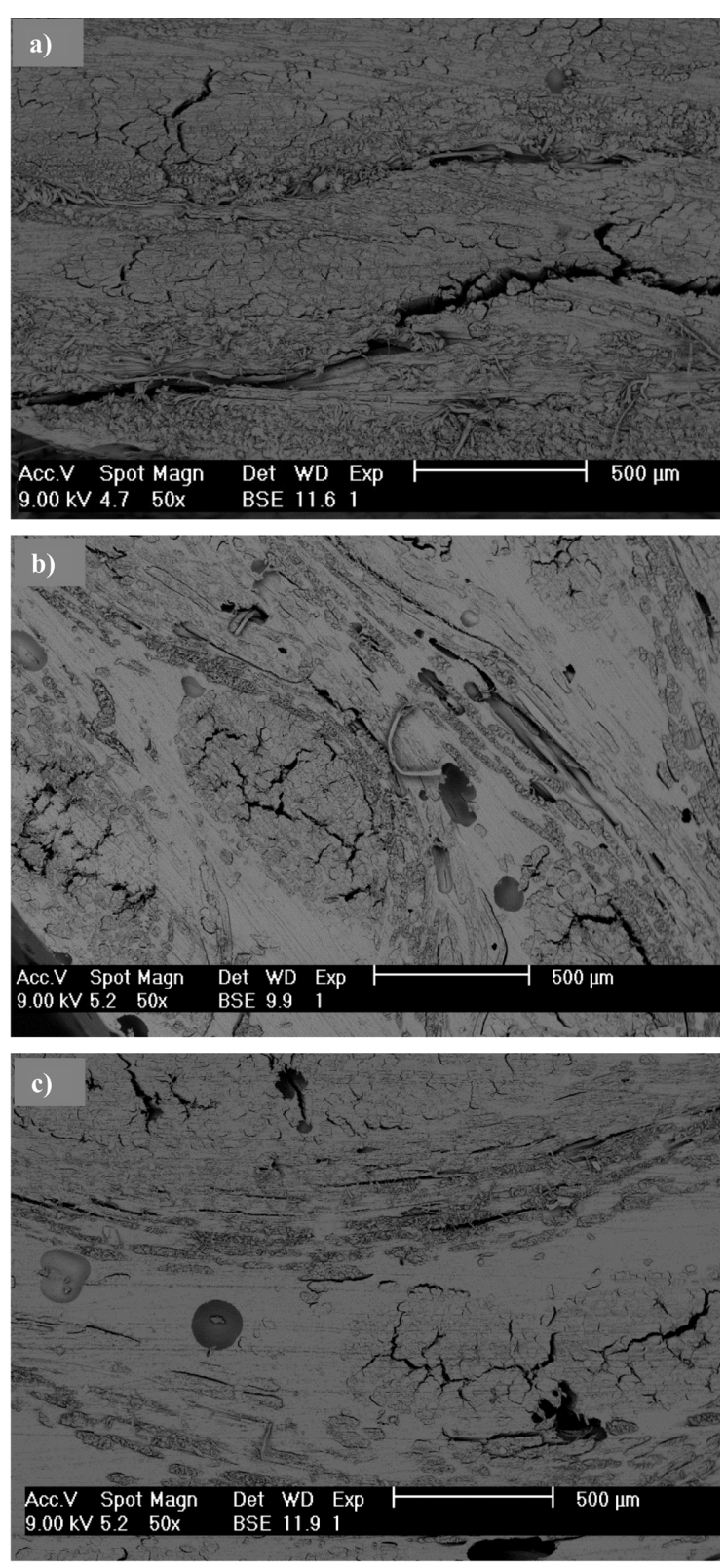

Figure 7. Cross section observations by SEM.

medium and coarse grammage, respectively. It is clear that composites manufactuvred by fine grammage shows poor adhesion and the presence of bigger defects, which had a decisive influence on the lower resistance and higher absorption of water in these composites. The adhesion can be improved by means fiber treatment. Bachtiar et $\mathrm{al}^{31}$ studied the flexural and impact properties of chemically treated $(4 \% \mathrm{NaOH}$ and $6 \% \mathrm{NaOH})$ sugar palm fiber/polystyrene composites and obtaind a significant increase in mechanical properties relative to the untreated composites.

Storage modulus (E') data were collected during the DMA tests.

Figure 8 shows the curves of the storage modulus (E') against the temperature. Each curve represents an average data of three specimens. As temperature increases, it is possible to

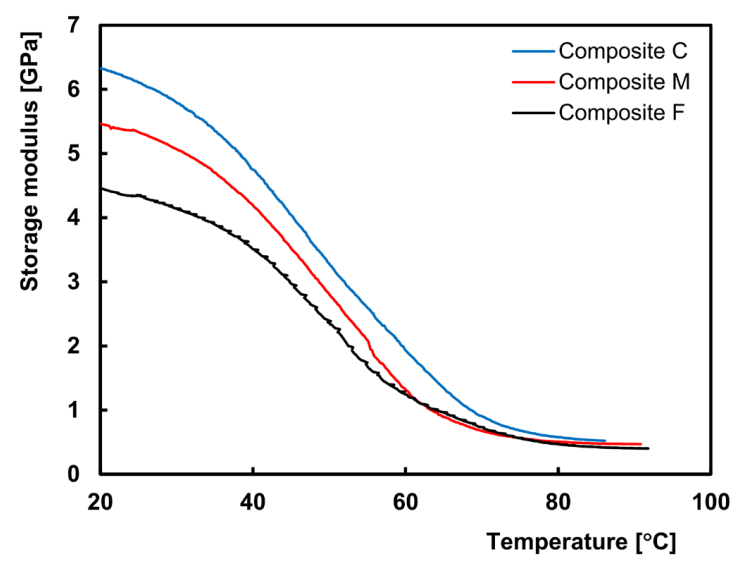

Figure 8. Average storage modulus (E') versus temperature.

observe a falling trend in the values of storage modulus (E'). A decrease in the storage modulus (E') indicates a decrease in the stiffness of the composites. For temperatures above $40^{\circ} \mathrm{C}$ it was observed a very sharp drop in the stiffness modulus. Despite the differences caused by intrinsic difference of methods, results obtained from DMA tests are in accordance with the results observed in the static tests and confirm the increase of the stiffness with the grammage.

Impact tests were carried out with incident impact energies from 1.1 to $5.5 \mathrm{~J}$. The time range for acquisition data was 6 microseconds. Figures 9 and 10 show some example of curves, in terms of the energy versus time and deformation versus time, respectively, obtained for the three composite compositions and impact energy values of 2 and $3 \mathrm{~J}$. These curves are representative of the performed tests and show the typical behavior for composite laminates, characterized by an increase in the absorbed energy, load and deformation up to a maximum value, followed by a drop. These figures also show significant differences in the impact responses of the three materials.

In the majority of the tests the impactor deforms the specimens and always rebounds, which means that the maximum impact energy was not high enough to produce full penetration. However, for higher impact energies a total perforation by impactor was achieved. The analysis of Figures 9 and 10 shows a strong influence of the type of jute in the impact response. It is very clear that increased grammage is associated with a strong increase in peak load and restored energy and a marked reduction of the deformation and time to reach the maximum load. As in the static tests, these results must be substantially conditioned by the increase of thickness obtained on the laminates with greater grammage.

Figure 11) shows the average values (and the minimum-maximum interval) of the peak load, in terms of absolute values, versus the incident impact energy, for all laminates. As expected, the peak load increases almost linearly with the impact energy until a perforation of the plates is observed, and afterwards peak load has a marked reduction. The energy required for perforation increases sharply with the laminate grammage, which is due to the increased thickness of the plates. According with previous 


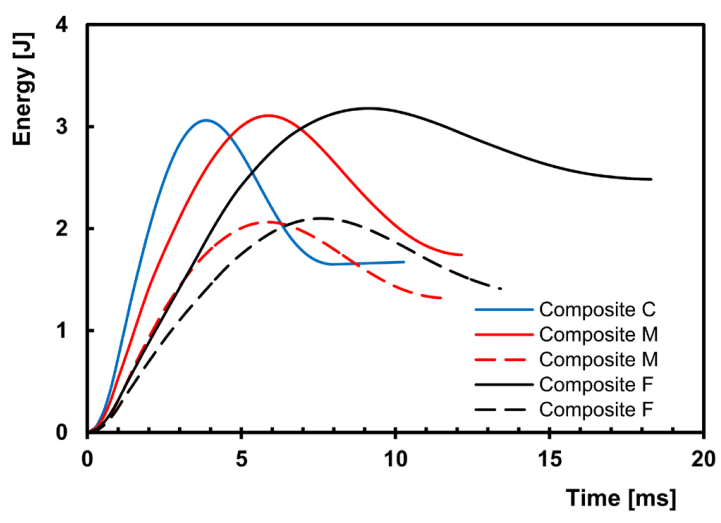

Figure 9. Exemplary curves of the energy versus time during impact tests.

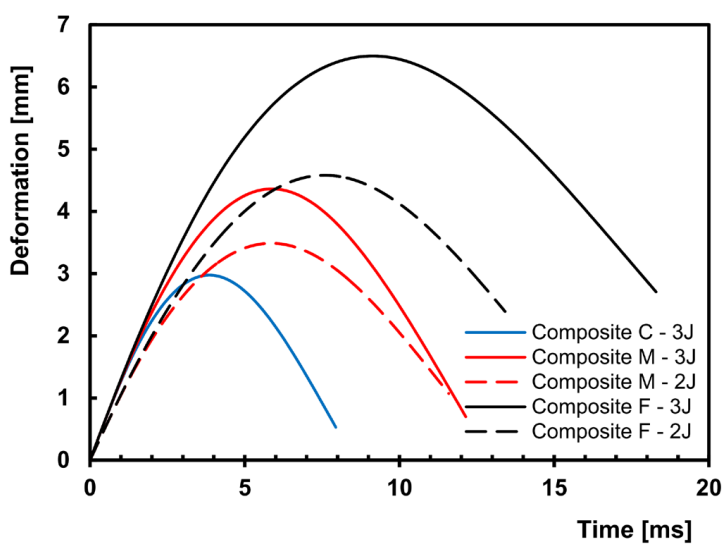

Figure 10. Examples of deformation curves versus time.

analysis, peak load increases significantly with the grammage of the laminate for a given impact energy, mostly due to the increased thickness and stiffness.

Fig. 12 shows the average values (and the minimummaximum interval) of the recovery energy versus the incident impact energy, for the three laminates. Recovery energy presents, obviously, an inverse tendency of that for absorbed energy. According to the results obtained for other types of composite formulations, recovery energy (in percentage of incident impact) tends to decrease with impact energy, as a consequence of increased damage occurrence until perforation. For this limit condition the recovery energy drops sharply to zero. A marked increasing of the perforation impact energy was obtained by increasing the fiber grammage and correspondent thickness of the laminates.

\section{Conclusions}

The static mechanical properties and impact response of a set of epoxy laminated composite plates with different types of jute fibers (Coarse, Medium and Fine) processed by vacuum bagging were characterized. The main conclusions are:

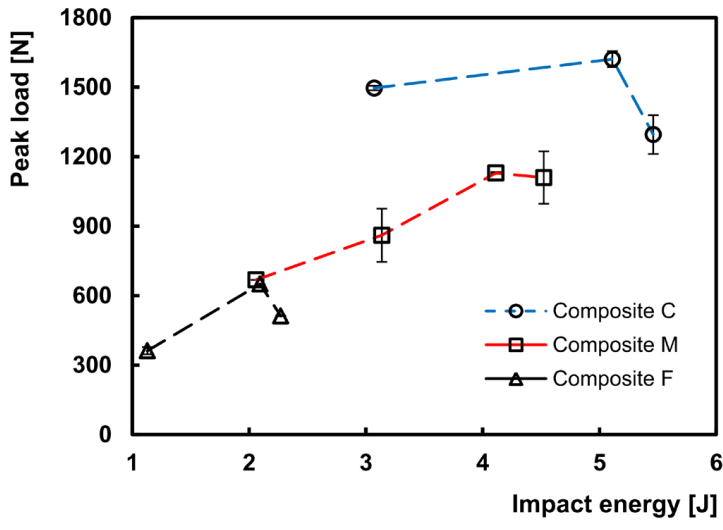

Figure 11. Peak load versus impact energy.

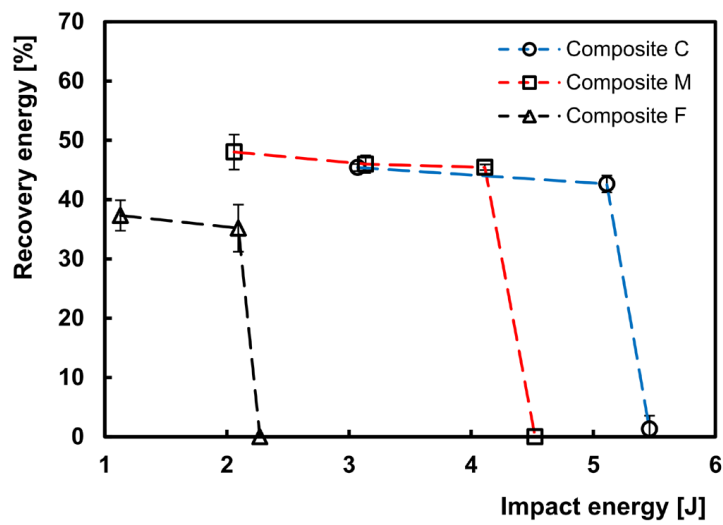

Figure 12. Recovery energy versus the impact energy.

- Once the vacuum pressure was maintained constant, the thickness of the composite laminates was largely determined by the grammage of the reinforcing fabrics. The bending mechanical properties and impact response was conditioned not only by the percentage of fiber, but mainly by the thickness of the specimens;

- Immersion in water causes a marked loss of mechanical properties in the first days of immersion due to the degradation of the fibers and interface, followed by a slight tendency to stabilization for higher immersion times. The loss of properties was much more marked for fine fiber grammage composites;

- Both long time immersed and not immersed specimens of composites $\mathrm{F}$ have bending strengths lower than composites $\mathrm{C}$, in spite of its similar percentage of fiber in volume, due to the role of thickness, porosity and fiber/polymer adhesion;

- A strong influence of the grammage on the impact response was observed. Increased grammage promotes 
a strong increase in peak load and restored energy, and a marked reduction of the deformation. The recovery energy slowly decreases with the impact energy increasing until perforation. A marked increasing of perforation impact energy was obtained with the increase of the fiber grammage.

\section{References}

1. Velmurugan R, Manikandan V. Mechanical properties of palmyra/glass fiber hybrid composites. Composites Part A: Applied Science and Manufacturing, 2007;38(10):2216. http:// dx.doi.org/10.1016/j.compositesa.2007.06.006

2. Akil HM, Omar MF, Mazuki AAM, Safiee S, Ishak ZAM, Abu Bakar A. Kenaf fiber reinforced composites: A review. Materials \& Design. 2011;32(8-9): 4107-4121. http://dx.doi. org/10.1016/j.matdes.2011.04.008.

3. Bledzki AK, Zhang W, Chate A. Natural-fibre-reinforced polyurethane microfoams. Composites Science and Technology. 2001;61(16):2405-2411. http://dx.doi.org/Composites Science and Technology. 2001;61(16):2405-2411.

4. Rashdi AAA, Sapuan SM, Ahmad MMHM, Khalina A. Combined effects of water absorbtion due to water immersion, soil buried and natural weather on mechanical properties of kenaf fibre unsaturated polyester composites (KFUPC). International Journal of Mechanical and Manufacturing Engineering, 2010;5(1):11-17.

5. Dash BN, Rana AK, Nayak SK, Mishra HK, Mishra SC, Tripathy SS. Novel, low-cost jute-polyester composites. Part 1: Processing, mechanical properties, and SEM analysis. Polymer Composites. 1999;20(1):62-71. http://dx.doi.org/10.1002/ pc. 10335 .

6. Jawaid M, Abdul Khalil HPS, Abu Bakar A. Woven hybrid composites: Tensile and flexural properties of oil palmwoven jute fibres based epoxy composites. Materials Science and Engineering: A. 2011;528(15):5190-5195.http://dx.doi. org/10.1016/j.msea.2011.03.047

7. Arbelaiz A, Fernández B, Ramos JA, Retegi A, Llano-Ponte $\mathrm{R}$, Mondragon I. Mechanical properties of short flax fibre bundle/polypropylene composites: Influence of matrix/fibre modification, fibre content, water uptake and recycling. Composites Science and Technology. 2005;65(10):1582-1592. http://dx.doi.org/10.1016/j.compscitech.2005.01.008.

8. Park JM, Quang ST, Hwang BS, DeVries KL. Interfacial evaluation of modified Jute and Hemp fibers/polypropylene (PP)-maleic anhydride polypropylene copolymers (PP-MAPP) composites using micromechanical technique and nondestructive acoustic emission Composites Science and Technology. 2006;66(15):26862699. http://dx.doi.org/10.1016/j.compscitech.2006.03.014.

9. Doan TTL, Brodowsky H, Mader E. Jute fibre/polypropylene composites II. Thermal, hydrothermal and dynamic mechanical behaviour. Composites Science and Technology. 2007;67(13):27072714. http://dx.doi.org/10.1016/j.compscitech.2007.02.011.

10. Madsen B, Hoffmeyer P, Thomsen AB, Lilholt H. Hemp yarn reinforced composites - I. Yarn characteristics. Composites Part A: Applied Science and Manufacturing. 2007;38(10):2194-2203. http://dx.doi.org/10.1016/j.compositesa.2007.06.001.

11. Park JM, Kim PG, Jang JH, Wang Z, Hwang BS, DeVries KL. Interfacial evaluation and durability of modified Jute fibers/polypropylene (PP) composites using micromechanical test and acoustic emission. Composites Part B: Engineering.

\section{Acknowledgments}

The authors thank the sponsoring of this research by FEDER funds through the program COMPETE - Programa Operacional Factores de Competitividade - and by national funds through FCT - Fundação para a Ciência e a Tecnologia -, under the project UID/EMS/00285/2013.

2008;39(6):1042-1061. http://dx.doi.org/10.1016/j. compositesb.2007.11.004.

12. Sgriccia N, Hawley MC, Misra M. Characterization of natural fiber surfaces and natural fiber composites. Composites Part A: Applied Science and Manufacturing . 2008;39(10):1632-1637. http://dx.doi.org/10.1016/j.compositesa.2008.07.007.

13. Satyanarayana K.G., Ramos L.P., Wypych F. Comparative study of Brazilian natural fibers and their composites with others. In: Natural Fibre Reinforced Polymer Composites. Old City Publishing Co: Philadelphia; 2009. p. 473-522.

14. Saha AK, Das S, Bhatta D, Mitra BC. Study of jute fiber reinforced polyester composites by dynamic mechanical analysis. Journal of Applied Polymer Science. 1999;71(9):1505-1513. http://dx.doi. org/10.1002/(SICI)1097-4628(19990228)71:9<1505::AIDAPP15>3.0.CO;2-1.

15. Alves C, Ferrão PMC, Silva AJ, Reis LG, Freitas M, Rodrigues LB, Alves DE. Ecodesign of automotive components making use of natural jute fiber composites. Journal of Cleaner Production. 2010;18(4):313-327. http://dx.doi.org/10.1016/j. jclepro.2009.10.022.

16. Khan MdN, Roy JK, Akter N, Zaman HU, Islam T, Khan RA. Production and Properties of Short Jute and Short E-Glass Fiber Reinforced Polypropylene-Based Composites. Open Journal of Composite Materials. 2012;2(2):40-47. http://dx.doi.org/ 10.4236/ojcm.2012.22006.

17. Eichhorn SJ, Baillie CA, Zafeiropoulos N, Mwaikambo LY, Ansell MP, Dufresne A. Review: Current international research into cellulosic fibres and composites. Journal of Materials Science. 2001;6(9):2107-2131. http://dx.doi.org/10.1023/A:1017512029696.

18. Tahir PM, Ahmed AB, Saifulazry SOA, Ahmed Z. Retting process of some bast plant fibres and its effect on fibre quality: a review. BioResources. 2011;6(4):5260-5281.

19. Jawaid M, Abdul Khalil HPS, Abu Bakar A. Woven hybrid composites: Tensile and flexural properties of oil palm-woven jute fibres based epoxy composites. Materials Science and Engineering: A. 2011;528(15):5190-5195. http://dx.doi. org/10.1016/j.msea.2011.03.047.

20. Bledzki A, Gassan KJ, Theis S. Wood-filled thermoplastic composites. Mechanics of Composite Materials. 1998;34(6):563568. http://dx.doi.org/10.1007/BF02254666.

21. Thwe MM, Liao K. Effects of environmental aging on the mechanical properties of bamboo-glass fiber reinforced polymer matrix hybrid composites. Composites Part A: Applied Science and Manufacturing. 2002;33(1):43-42. http://dx.doi.org/10.1016/ S1359-835X(01)00071-9.

22. Tajvidi M., Ebrahimi G. Water uptake and mechanical characteristics of natural filler-polypropylene composites. Journal of Applied Polymer Science. 2003;88(4):941-946. http://dx.doi.org/10.1002/app.12029.

23. Yadav P, Nema A, Varghese S, Nema SK. Newspaperreinforced plastic composite laminates: Mechanical and water uptake characteristics. Polymer Engineering and Science. 1999;39(8):1550-1557. http://dx.doi.org/10.1002/pen.11548

24. Pothan LA, Thomas S. Effect of hybridization and chemical modification on the water-absorption behavior of banana fiber- 
reinforced polyester composites. Journal of Applied Polymer Science. 2004;91(6):3856-3865. http://dx.doi.org/10.1002/ app.13586.

25. Yang Y, Ota T, Morii T, Hamada H. Mechanical property and hydrothermal aging of injection molded jute/polypropylene composites. Journal of Materials Science. 2011;46(8):26782684. http://dx.doi.org/10.1007/s10853-010-5134-8.

26. Girisha C, Sanjeevamurthy G, Srinivas GR. Sisal/Coconut Coir Natural Fibers - Epoxy Composites: Water Absorption and Mechanical Properties. International Journal of Engineering and Innovative Technology (IJEIT). 2012;2(3):166-170.

27. Backfolk K, Holmes R, Ihalainen P, Sirvio P, Triantafillopoulos $\mathrm{N}$, Peltonen J. Determination of the glass transition temperature of latex films: Comparison of various methods. Polymer Testing. 2007;26(8):1031-1040. http://dx.doi.org/10.1016/j. polymertesting.2007.07.007.

28. Leman Z, Sapuan SM, Saifol AM, Maleque MA, Ahmad MMHM. Moisture absorption behavior of sugar palm fiber reinforced epoxy composites. Materials \& Design.2008;29(8):16661670. http://dx.doi.org/10.1016/j.matdes.2007.11.004.

29. Espert A, Vilaplana F, Karlsson S. Comparison of water absorption in natural cellulosic fibres from wood and one-year crops in polypropylene composites and its influence on their mechanical properties. Composites Part A: Applied Science and Manufacturing. 2004;35(11):1267-1276. http://dx.doi. org/10.1016/j.compositesa.2004.04.004

30. Rimdusit S, Jubsilp C, Tiptipakorn S. Newly High-Performance Wood-Substituted Composites Based on Polybenzoxazines. In: Alloys and composites of polybenzaxazines: properties and applications. Singapore: Springer; 2013. p. 83-115. Doi. org/10.1007/978-981-4451-76-5

31. Bachtiar D, Sapuan SM, Khalina A, Zainudin ES, Dahlan KZM. Flexural and impact properties of chemically treated sugar palm fiber reinforced high impact polystyrene composites. Fibers and Polymers. 2012;13(7):894-898. http://dx.doi.org/10.1007/ s12221-012-0894-1. 